\title{
GOVERNANÇA TERRITORIAL: UM CAMINHO PARA A SUSTENTABILIDADE DAS COMUNIDADES. DEFINIÇÃO DE UM MÉTODO DE MEDIÇÃO QUALITATIVA DE INSTRUMENTOS DE GOVERNANÇA. ESTUDO DE CASO: PARCERIAS PÚBLICO-PRIVADAS EM PORTUGAL
}

\author{
Lucinda Oliveira Caetano ${ }^{1}$
}

\begin{abstract}
RESUMO
Os documentos estratégicos para a Europa 2020 e consequentemente para Portugal 2020 reforçam a necessidade de se promover uma economia inteligente, sustentável e inclusiva, que proporcione níveis elevados de emprego, de produtividade e de coesão social. $\mathrm{Na}$ agenda das políticas públicas para os territórios incluem-se conceitos como governança, abordagem de base local e sustentabilidade. O objetivo desta investigação é criar/ testar uma grelha de leitura que articule as dimensões da governança com os vetores estratégicos da sustentabilidade, para aferir/mensurar a qualidade dos instrumentos de governança. A nossa questão central parte da premissa de que a GOVERNANÇA TERRITORIAL aporta um caminho para a SUSTENTABILIDADE territorial e humana. O método utilizado será a análise interpretativa de dados recolhidos na literatura temática para criação da grelha de leitura. O resultado da aplicação da grelha de leitura a um estudo de caso Parcerias público-privadas - parece corroborar a nossa premissa de partida, que uma vez testada empiricamente, poderá tornar-se uma ferramenta útil na operacionalização das políticas públicas. Em síntese, o estudo procurou delimitar, no âmbito da sustentabilidade, alguns fatores prioritários para operacionalizar no território as políticas públicas. Nesse âmbito os governos locais deverão pugnar pela assunção de uma visão estratégica que articule o planeamento urbanístico com a governança territorial, numa ótica de sustentabilidade económica, ambiental e humana.
\end{abstract}

PALAVRAS-CHAVE: Governança. Território. Sustentabilidade.

\section{TERRITORIAL GOVERNANCE: A PATH TO SUSTAINABLE COMMUNITIES. DEFINITION OF A QUALITATIVE METHOD OF MEASURING GOVERNANCE TOOLS. CASE STUDY: PUBLIC- PRIVATE PARTNERSHIPS IN PORTUGAL}

\footnotetext{
${ }^{1}$ Arquiteta (Universidade Federal do Rio de Janeiro/ Universidade do Porto), mestre em História da Arte (Universidade Federal do Rio de Janeiro/ Universidade Nova de Lisboa) e doutoranda em Urbanismo pela Faculdade de Arquitetura (FA) da Universidade de Lisboa e investigadora no CIAUD Centro de Investigação em Arquitetura, Urbanismo e Design. E-mail: lucinda.caetano63@gmail.com
} 
Revista Nacional de

\begin{abstract}
Strategic documents for Europe 2020 and thus to Portugal in 2020 reinforce the need to promote smart, sustainable and inclusive economy which promotes high levels of employment, productivity and social cohesion. On the agenda of public policies for the territories it is included concepts such as governance, place-based approach and sustainability. The purpose of this research is to create / test a reading frame which sets forth dimensions of governance with strategic vectors of sustainability, to assess / measure the quality of governance tools. Our central question assumes that the TERRITORIAL GOVERNANCE favors a way for territorial and human SUSTAINABILITY. The method used will be the interpretative analysis of data collected in the thematic literature in order to create a reading frame. The result of the reading frame of the application to a case study - Public-private partnerships - seems to corroborate our starting premise, which once tested empirically, could become a useful tool in the implementation of public policies. Summing up, the study sought to set out, within sustainability, some priority factors to operate in the territory of public policy. In this context, local governments should strive to acquire a strategic vision which articulates urban planning with territorial governance, from the point of view of economic, environmental and human sustainability.
\end{abstract}

KEYWORDS: Governance. Territory. Sustainability.

\title{
GOBERNANZA TERRITORIAL: UN CAMINO HACIA COMUNIDADES SOSTENIBLES. DEFINICIÓN DE UN MÉTODO CUALITATIVO DE INSTRUMENTOS DE MEDICIÓN DE GOBERNABILIDAD. ESTUDIO DE CASO: ASOCIACIONES PÚBLICO-PRIVADAS EN PORTUGAL
}

\begin{abstract}
RESUMEN
Documentos estratégicos para Europa 2020, y por lo tanto para Portugal en 2020, reforzaron la necesidad de promover la economía inteligente, sostenible e integradora que disfrute de altos niveles de empleo, productividad y cohesión social. En la agenda de las políticas públicas de los territorios se pretende incluir conceptos como la gobernanza, el enfoque basado en el lugar y la sostenibilidad. El propósito de esta investigación es crear/probar un marco de lectura que establezca dimensiones de gobernabilidad con los vectores estratégicos de la sostenibilidad, para evaluar/medir la calidad de los instrumentos de gobernanza. Nuestra cuestión central asume que la gobernanza territorial aporta un camino para la SOSTENIBILIDAD territorial y humana. El método utilizado será el análisis interpretativo de los datos recogidos en la bibliografía temática para el marco de lectura de la creación. El resultado de la fase de lectura de la aplicación a un caso de estudio -las asociaciones público-privadas- parece corroborar nuestra premisa de partida, que una vez probada empíricamente, podría convertirse en una herramienta útil en la implementación de políticas públicas. En resumen, el estudio trata de establecer en el plazo de sostenibilidad, algunos factores prioritarios que operan en el territorio de las políticas públicas. En este contexto, los gobiernos locales deben luchar por la adquisición de una visión estratégica que articule la planificación urbana con la gobernanza territorial, desde un punto de vista económico, ambiental y humano.
\end{abstract}

PALABRAS CLAVE: Gobernabilidad. Territorio. Sostenibilidad. 


\section{Revista Nacional de}

Gerenciamento de Cidades

\section{INTRODUÇÃO}

Este trabalho constitui-se como uma reflexão teórica sobre a GOVERNANÇA TERRITORIAL, cujo argumento pretende evidenciar algumas pistas que nos conduzem à ideia de que possa ser um caminho para a sustentabilidade das comunidades.

Na nossa ótica, a investigação desta temática é bastante pertinente, em especial numa conjuntura mundial de crise económica, onde prepondera a desconfiança geral relativamente à capacidade dos Estados em garantir a sustentabilidade das cidades e das comunidades.

O artigo começa por apresentar uma visão geral da problemática que se pretende abordar: governança, território e sustentabilidade.

De seguida formulamos as questões de investigação e descrevemos o método de pesquisa. A partir da análise e interpretação dos dados recolhidos na revisão literária iremos evidenciar e testar a nossa grelha de leitura num estudo de caso e de seguida apresentaremos os resultados da investigação. Após a análise dos resultados passaremos às conclusões.

\section{CONTEXTO}

Os documentos estratégicos da comunidade européia definem uma visão para o horizonte de 2020 baseada numa economia inteligente, sustentável e inclusiva, através de um quadro de governação mais forte.[1]

Nessa ótica, "abordagem integrada no desenvolvimento urbano é necessariamente de base local e com o foco no território, enfatizando uma 


\section{Revista Nacional de}

confluência estratégica e operacional entre as diferentes políticas sectoriais e o próprio desenvolvimento urbano. ${ }^{2}$ (T.A.) [2]

Nas orientações européias para a sustentabilidade urbana/ territorial são identificados quatro princípios de base a ser aplicados pelos governos locais. [3]

Contudo, apesar destas orientações serem transplantadas para os documentos estratégicos, e consequentemente para as políticas públicas dos Estados-membros, em Portugal, ainda não há resultados evidentes devido a dificuldades de operacionalização. [4]

O objetivo deste trabalho é construir uma grelha de leitura que possa ser testada, com o intuito de contribuir para uma melhor operacionalização das políticas públicas.

\section{MÉTODO}

O percurso que delineamos na nossa reflexão pretende responder a estas quatro perguntas: Como? Onde? e Para quê?

\section{COMO? GOVERNANÇA}

Governança enquanto atividade para "governar" de modo coerente, articulado e participado [5]

Em termos teóricos percebe-se que CRESPO opõe a ideia de governança "assumida como nova governança" ao modelo tradicional de governar, procurando encontrar influências e a utilização de instrumentos de gestão inovadores (relacionados com parcerias e participação pública) nas políticas públicas em especial nas políticas urbanas e na gestão autárquica.

\footnotetext{
${ }^{2} 1$ an integrated approach in urban development is necessarily a place-based and territory-focused approach, stressing for a strategic and operational confluence between the different sector-wide policies and the urban development itself
} 
O estudo científico de HALL [6] define as estruturas de governança em quatro categorias distintas: Hierarquia; Mercados, Redes e Comunidades. Na sua ótica, usando como referencial essa grelha de análise parte de uma situação de controlo absoluto (hierarquias) até uma situação de autorregulação (comunidades) ou "não-governo". Os mercados representam os agentes económicos e as redes a articulação entre Entidades públicas e privadas.

Relativamente ao conteúdo de "governança" da revisão literária até agora realizada verifica-se um amplo espectro temático sobre o assunto. Contudo, feita a seleção pode-se classificar, grosso modo, em quatro faces distintas ou "dimensões de abordagem": Política e Políticas Públicas [7] [8] [9]; Políticas de Base Local [10] [11] [12], Planeamento Estratégico e Urbanístico [13] [14] [15] [16] [17] [18]; e Governança enquanto nova Gestão Pública [19] [20] [21] [22]. Alguns autores inclusive abordam simultaneamente duas faces na sua conceção de governança.

A nós parece-nos sensato assumir que a governança será tanto melhor quanto maior o número de incidências dimensionais, como aliás demonstraremos mais à frente ao analisar o estudo de caso.

De sublinhar que as quatro dimensões, partem da visão macro para a operacionalização no território das políticas públicas, onde as estratégias patentes nas políticas territoriais, deverão ser adaptadas aos contextos locais, para operacionalizá-las através dos instrumentos de planeamento, coordenados e geridos pela administração pública, enquanto organização técnico-administrativa.

\section{DIMENSÃO 1 - Política e Políticas Públicas}

Partindo da dimensão supra, selecionamos alguns autores que vinculam a Governança à legitimação política, desde Alford e Friedland [7] que consideram que intrínseco ao poder encontram-se as contradições entre as instituições políticas e as burocráticas, passando por Bevir [8] que a justifica como "remédio" para os males da democracia contemporânea, que sofre tanto com os limites difusos da accountability 
quanto com a legitimidade declinante e terminamos com a "mensagem" provocatória de Rose COMPANS [9], quado avalia os "modelos de gestão urbana" no âmbito dos "modelos de empreendedorismo competitivo", onde deixariam de ser um instrumento "técnico", para constituírem uma estratégia político-argumentativa destinada a viabilizar um "novo" projeto de modernização capitalista.

\section{DIMENSÃO 2 - Políticas de base local}

Para clarificar esta dimensão selecionamos três autores que nos parecem suficientemente representativos.

EVANS et all [10], que consideram que o localismo representa a "devolução do poder a estruturas democráticas locais, instituições e comunidades locais". Por sua vez, BOSCHI [11], na sua análise comparativa de governança urbana entre Belo Horizonte e Salvador, considera que a integração governativa ao local promove a gestão descentralizada fundada na cooperação público-privada e na utilização de mecanismos de accountability. Relativamente a governança enquanto política territorial de base local, encontra-se definida com maestria por CAVACO [12], no seu artigo sobre "política para cidade compacta", como abordagem territorial integrada, ou parafraseando BARCA [2] como abordagem baseada no local, em multi-escala, multinível, multissetorial e multiagentes.

\section{DIMENSÃO 3 - Planeamento Estratégico e Urbanístico}

Esta terceira dimensão da governança é a que apresenta mais adeptos, principalmente em solo português. No discurso pressente-se que a argumentação dos seus defensores inspira-se nos resultados obtidos através do planeamento participativo em contextos europeus, estando na base dos mais recentes diplomas e documentos estratégicos, "inovadores" em termos de gestão. A autora Sónia ALVES [13] na sua tese de doutoramento, ao debruçar-se sobre a regeneração urbana de 


\section{Revista Nacional de}

duas zonas da cidade do Porto, concluiu que governança (no sentido de boa governação) equivale ao planeamento estratégico aliado ao comprometimento político. Por sua vez, Idalina BAPTISTA [14], ao analisar a implementação do Programa POLIS, vincula a governança urbana ao planeamento, salientando que a forma como está sistematizada quer as legitimidades de participação, quer as práticas vigentes só poderá ser inteligível se visto à luz da perceção de que Portugal é um "país desordenado"3.

João CABRAL et all [15], propõem alguns mecanismos por configurarem uma Governação multinível que asseguram processos democráticos de participação e tomada de decisão. Aliás, na elaboração do Programa Nacional da Política de Ordenamento do Território (PNPOT) esteve presente essa governança ou "estratégia governativa", conforme definido por Cristina Cavaco [4], no entanto, a "governança" não teve continuidade, uma vez que não foram concretizados os Planos de Ação preconizados no PNPOT.

Finalizamos a ilustração desta dimensão com HEALEY [18] que ao explorar a natureza do planeamento estratégico o vê como um planeamento associado a um estilo de governação com orientação política.

\section{DIMENSÃO 4 - Governança enquanto nova Gestão Pública}

Para ilustrar a Dimensão 4 referenciamos quatro autores, com formações distintas, vivendo em contextos distintos, que se reportam à governança como melhoria na organização administrativa pública, sem ligação direta ao território, ou seja, o conteúdo remete-nos para a adoção de valores e boas práticas "empresariais" na administração pública, garantindo deste modo a prestação de um melhor serviço público, ou no dizer de COMPANS [9] para modelos de empreendedorismo competitivo.

\footnotetext{
${ }^{3}$ De facto tem-se notícias de que em alguns projetos algarvios, integrados no Programa POLIS, as iniciativas de participação pública e parcerias foram escassas ou inexistiram.
} 
Os autores Manuel CARVALHO (Portugal) [19], Luís AGUILAR (México) [20] e João BILHIM (Portugal) [22] vinculam governança à nova gestão da administração pública, definido por CARVALHO como governação interna e externa na administração local, e que nas palavras de AGUILAR assume-se como uma nova relação diretiva entre governo e sociedade, onde a administração pública aporta "questões relativas à capacidade e eficácia diretiva do governo", enquanto BILHIM a vê como a gestão eficiente e eficaz da estrutura do Estado que permite um serviço público de maior qualidade e a custos mais baixos. Contudo o brasileiro Luiz ANDRADE [21] ao debruçar-se sobre o estabelecimento de sistemas universais de saúde acrescenta uma outra característica à governança a de "processo", ou seja, constitui-se como o processo contínuo de gestão, avaliação e tomada de decisão.

\section{ONDE? TERRITÓRIO - Qual a definição ?}

A definição de Território no contexto deste artigo contém vários atributos, enquanto definição/ conceito e como "lugar" onde se materializam as políticas públicas.

Antes de definirmos território julga-se pertinente refletir sobre a "cidade" enquanto entidade, uma vez que é o lugar por excelência de assentamentos humanos no nosso planeta globalizado, onde "uma cidade será sempre um sistema complexo onde convergem, de uma forma integrada, uma série de funções e subsistemas urbanos, continuamente sujeitos a uma multiplicidade de processos interdependentes" (T.A.) ${ }^{4}$ [23] [12]

\section{A definição}

\footnotetext{
${ }^{4}$ a city is always a complex system to which converge, in an integrated way, a series of functions and urban subsystems, continuously subject to a multitude of interdependent processes.
} 
Do conceito de cidade passamos ao de território "essa entidade física e mental" e o território é simultanemanete um processo $/ . \ldots /$ um produto $/ . . . /$ e um projeto /.../ Como tal, reúne o artefato físico mais os processos e os projetos que o moldam. [24] [12]

\section{Lugar de materialização das políticas públicas}

O macro objetivo da COMUNIDADE EUROPEIA é o da territorialização das políticas públicas. [25] Em suma, as políticas de base local, uma das facetas da governança terão necessariamente que estar implicadas com o território enquanto processo, produto e projeto.

\section{Governança Territorial}

A abordagem integrada no desenvolvimento urbano é necessariamente de base local e com o foco no território, enfatizando uma confluência estratégica e operacional entre as diferentes políticas sectoriais e o próprio desenvolvimento urbano. (T.A.) $)^{5}$.[2] [12].

Outra definição sobre governança urbana/ territorial encontra-se na UNHABITAT que a define como um processo contínuo que informa o sucesso de um sistema de cidade, ou seja, "como as muitas maneiras como as instituições e os indivíduos organizam a gestão do dia-a-dia de uma cidade e quais os processos que utilizam para efetivamente realizar a curto e a longo prazo a agenda de desenvolvimento de uma cidade "(T.A. $)^{6}$

\footnotetext{
${ }^{5}$ An integrated approach in urban development is necessarily a place-based and territory-focused approach, stressing for a strategic and operational confluence between the different sector-wide policies and the urban development itself.

${ }^{6}$ Urban governance can be defined as the many ways that institutions and individuals organise the day-to-day management of a city and the processes used for effectively realising the short term and long-term agenda of a city's development. IN: www: http://unhabitat.org/urban-themes/governance/ [Accessed February 05, 2015].
} 


\section{A nossa definição}

Governança territorial é o método de governar um território específico (com as suas potencialidades e fragilidades), com uma visão integrada e articulada, através da coordenação em rede e em parceria com as comunidades e os mercados.

\section{PARA QUÊ? SUSTENTABILIDADE}

O relatório sobre CIDADES EUROPEIAS SUSTENTÁVEIS elaborado pelo grupo de peritos sobre o ambiente urbano da Comissão Europeia em 1996, apresenta um quadro de acção para os governos locais e identifica quatro princípios a usar no estabelecimento de metas e na medição e acompanhamento dos progressos em direção à sustentabilidade nas zonas urbanas [26], nomeadamente:

\section{Princípio de integração política}

A coordenação e integração serão realizadas por meio da combinação do princípio de subsidiariedade com o conceito mais vasto da responsabilidade partilhada.

\section{Princípio de reflexão ecossistémica}

A reflexão ecossistémica mostra a cidade como um sistema complexo que é caracterizado por processos contínuos de transformação e desenvolvimento. /.... Esta inclui também uma dimensão social, que considera cada cidade como um ecossistema social.

\section{Princípio de gestão urbana}

O processo de gestão urbana sustentável requer uma série de instrumentos orientados para as dimensões ecológica, social e económica com vista a proporcionar a base necessária para a integração. 


\section{Princípio de cooperação e parceria}

A sustentabilidade é uma responsabilidade partilhada. A cooperação e parceria entre diferentes níveis, organizações e interesses são elementos essenciais da ação em prol da sustentabilidade.

Como refere o relatório - $\mathrm{O}$ desafio da sustentabilidade urbana é procurar solucionar tanto os problemas que as cidades conhecem como os por elas causados, reconhecendo que as próprias cidades encontram muitas soluções potenciais, em vez de os deslocar para escalas ou localizações diferentes ou de os transferir para as gerações futuras. Os padrões organizativos e sistemas administrativos dos municípios deverão adotar a perspetiva holística da reflexão ecossistémica

\section{QUESTÃO PRINCIPAL}

É legítimo afirmar que a governança territorial aporta um caminho para a sustentabilidade das comunidades?

\section{QUESTÕES DE INVESTIGAÇÃO}

Questão 1: É possível criar-se uma grelha de leitura capaz de demonstrar que os princípios orientadores da sustentabilidade urbana/ territorial integram a matriz da governança territorial e podem ser mensuráveis? 
Revista Nacional de

Gerenciamento de Cidades

Quadro 1: Correlação dos princípios da sustentabilidade com as dimensões da governança

\begin{tabular}{|c|c|c|c|c|}
\hline \multirow[b]{2}{*}{$\begin{array}{l}\text { Princípio/ } \\
\text { Dimensão da } \\
\text { governança }\end{array}$} & \multicolumn{2}{|c|}{ CIDADES EUROPEIAS SUSTENTÁVEIS } & \multicolumn{2}{|c|}{ GOVERNANÇA } \\
\hline & Conteúdo & Princípio & Dimensão & $\begin{array}{l}\text { Argumentação } \\
\text { Literária }\end{array}$ \\
\hline $\begin{array}{l}\text { Política/ macro } \\
\text { dimensão }\end{array}$ & $\begin{array}{l}\text { Princípio de subsidiariedade } \\
\text { com a responsabilidade } \\
\text { partilhada e articulação } \\
\text { horizontal e vertical }\end{array}$ & $\begin{array}{l}\text { Integração } \\
\text { política }\end{array}$ & $\begin{array}{l}\text { Política \& } \\
\text { Políticas } \\
\text { públicas }\end{array}$ & $\begin{array}{l}\text { Estratégia político- } \\
\text { argumentativa onde se } \\
\text { encontram presentes os } \\
\text { elementos constituintes do } \\
\text { Estado ocidental } \\
\text { contemporâneo - democracia, } \\
\text { burocracia e capitalismo }\end{array}$ \\
\hline $\begin{array}{l}\text { Ecossistema/ } \\
\text { mega dimensão }\end{array}$ & $\begin{array}{l}\text { Cada cidade é um } \\
\text { ecossistema social, } \\
\text { caracterizado por processos } \\
\text { contínuos de transformação } \\
\text { e desenvolvimento }\end{array}$ & $\begin{array}{c}\text { Reflexão } \\
\text { ecossistémic } \\
\text { a }\end{array}$ & $\begin{array}{l}\text { Políticas de } \\
\text { base local \& } \\
\text { associativismo }\end{array}$ & $\begin{array}{l}\text { Vinculação à comunidade e } \\
\text { aos agentes económicos, } \\
\text { através de uma abordagem } \\
\text { baseada no local, em multi- } \\
\text { escala, multinível e } \\
\text { multissetorial }\end{array}$ \\
\hline $\begin{array}{l}\text { Gestão/ média } \\
\text { dimensão }\end{array}$ & $\begin{array}{l}\text { Planeamento prévio com } \\
\text { atuação integrada das } \\
\text { dimensões ecológica, social } \\
\text { e económica }\end{array}$ & $\begin{array}{l}\text { Gestão } \\
\text { urbana }\end{array}$ & $\begin{array}{l}\text { Planeamento } \\
\text { estratégico \& } \\
\text { urbanístico }\end{array}$ & $\begin{array}{l}\text { Planeamento com orientação } \\
\text { e compromisso político e } \\
\text { participado }\end{array}$ \\
\hline $\begin{array}{l}\text { Cooperação/ } \\
\text { micro dimensão }\end{array}$ & $\begin{array}{l}\text { "Gestão sustentável", } \\
\text { enquanto processo de } \\
\text { aprendizagem, cujos } \\
\text { "padrões organizativos e os } \\
\text { sistemas administrativos dos } \\
\text { municípios" devem ser mais } \\
\text { flexíveis e eficazes }\end{array}$ & $\begin{array}{c}\text { Cooperação } \\
\text { e parceria }\end{array}$ & $\begin{array}{l}\text { Nova gestão } \\
\text { pública } \\
\text { \& Governança } \\
\text { empresarial }\end{array}$ & $\begin{array}{l}\text { Melhoria na gestão pública } \\
\text { administrativa, através da } \\
\text { adoção de valores e boas } \\
\text { práticas "empresariais" na } \\
\text { administração pública, } \\
\text { garantindo deste modo a } \\
\text { prestação de um melhor } \\
\text { serviço público }\end{array}$ \\
\hline
\end{tabular}

Fonte: CAETANO, 2015 [28]

Questão 2: É possível testar essa matriz com algum caso concreto? Com que caso de estudo?

Como instrumento de governança selecionamos as parcerias públicoprivadas (PPP) por estarem na agenda das políticas públicas, sendo instrumentos de governança cada vez mais utilizados pelos governos, em especial no fornecimento de serviços de infraestruturas urbanas, numa conjuntura económica cada vez mais deficiente em termos de capital público ${ }^{7}$, que serão caracterizadas no âmbito das quatro dimensões da governança através de análise interpretativa.

A metodologia utilizada na verificação dos dados da grelha de leitura, será baseada no método delineado para a Avaliação Ambiental Estratégica (AAE),ou

\footnotetext{
${ }^{7}$ O World Bank considera que as PPPs são uma forma de contratação de serviços públicos inovadora que recorre à experiência e ao suporte financeiro do setor privado, e que se implementadas corretamente poderão melhorar a prestação de serviços e facilitar o crescimento económico. [29]
} 

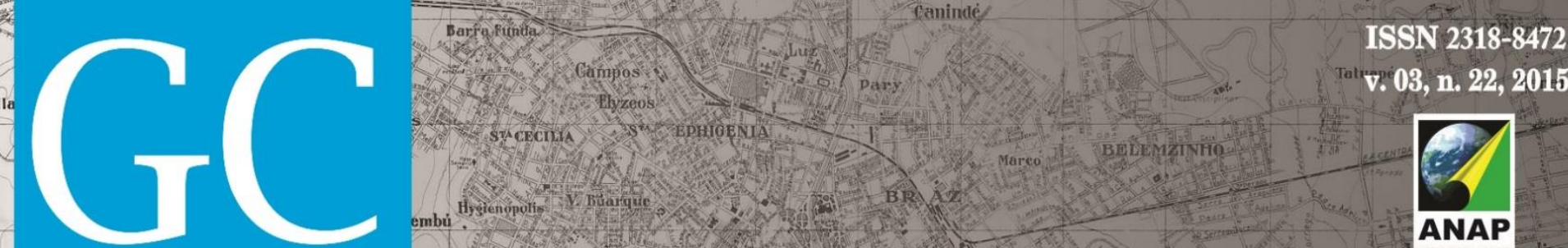

Revista Nacional de

Gerenciamento de Cidades

seja, considera-se a qualidade maior, quanto maior for o número de incidências, cujo máximo (ou situação idealizada) será a incidência na totalidade das dimensões da Governança.

Portanto, para responder à questão 2 iremos sistematizar a análise interpretativa seguindo duas etapas sequenciais, nomeadamente:

1. Primeira etapa: Enquadramento e definição das caraterísticas inerentes às tipologias de PPP's nas quatro dimensões da governança;

2. Segunda etapa: Diagnóstico da situação corrente nas PPP's em Portugal, através da verificação do grau de incidência, cujo resultado deverá articularse com as características assinaladas na primeira etapa.

\section{PRIMEIRA ETAPA}

\section{Conteúdo das tipologias de PPP's nas quatro dimensões da governança}

Para explicitar com maior pormenor as características que cada tipologia ${ }^{8}$ assume na integração às dimensões da governança apresentamos o Quadro 2, onde discriminamos o respetivo conteúdo.

Quadro 2: Conteúdo das tipologias de PPP's nas dimensões da governança

\begin{tabular}{|c|c|c|c|}
\hline $\begin{array}{l}\text { DIMENSÕES } \\
\text { GOVERNANÇA }\end{array}$ & CONTEÚDO & TIPOLOGIAS PPPs & Características \\
\hline \multirow{5}{*}{$\begin{array}{c}\text { Política \& } \\
\text { Políticas públicas }\end{array}$} & \multirow{5}{*}{$\begin{array}{c}\text { Definição } \\
\text { estratégica } \\
\text { alinhada com } \\
\text { as diretrizes } \\
\text { das Nações } \\
\text { Unidas e da } \\
\text { Europa, } \\
\text { integrado no } \\
\text { sistema } \\
\text { jurídico, com } \\
\text { reflexos } \\
\text { territoriais }\end{array}$} & $\begin{array}{l}\text { Orçamento } \\
\text { Participativo }\end{array}$ & $\begin{array}{l}\text { Valores da democracia participativa, constantes do } \\
\text { artigo } 2^{\circ} \text { e } 48.0 \text { da Constituição da República } \\
\text { PortuguesaFolha }\end{array}$ \\
\hline & & Empreitadas ou terceirização & $\begin{array}{l}\text { Código da Contratação pública (DL 18/2008, com as } \\
\text { alterações posteriores) }\end{array}$ \\
\hline & & $\begin{array}{l}\text { Contratos de planeamento e } \\
\text { reabilitação }\end{array}$ & $\begin{array}{l}\text { RJIGT (DL 80/2015) e RJRU (DL 307/ 2009,com as } \\
\text { alterações posteriores) }\end{array}$ \\
\hline & & $\begin{array}{l}\text { Concessão de serviços e } \\
\text { infraestruturas }\end{array}$ & $\begin{array}{l}\text { Diplomas próprios (RCM, DL, Leis ou Contratos de } \\
\text { Concessão) }\end{array}$ \\
\hline & & $\begin{array}{l}\text { Flls e empresas de capital } \\
\text { misto }\end{array}$ & $\begin{array}{l}\text { Orçamento de Estado } 2008 \text { e } 2009 \text {, RJRU e Decreto- } \\
\text { Lei } n .0 \text { 111/2012, de } 23 \text { de maio }\end{array}$ \\
\hline
\end{tabular}

\footnotetext{
${ }^{8}$ Sublinha-se que a seleção das tipologias de PPP'ss são resultante de uma revisão literária prévia, que consideramos desnecessário referi-la no âmbito do presente artigo. CF CAETANO [28]
} 


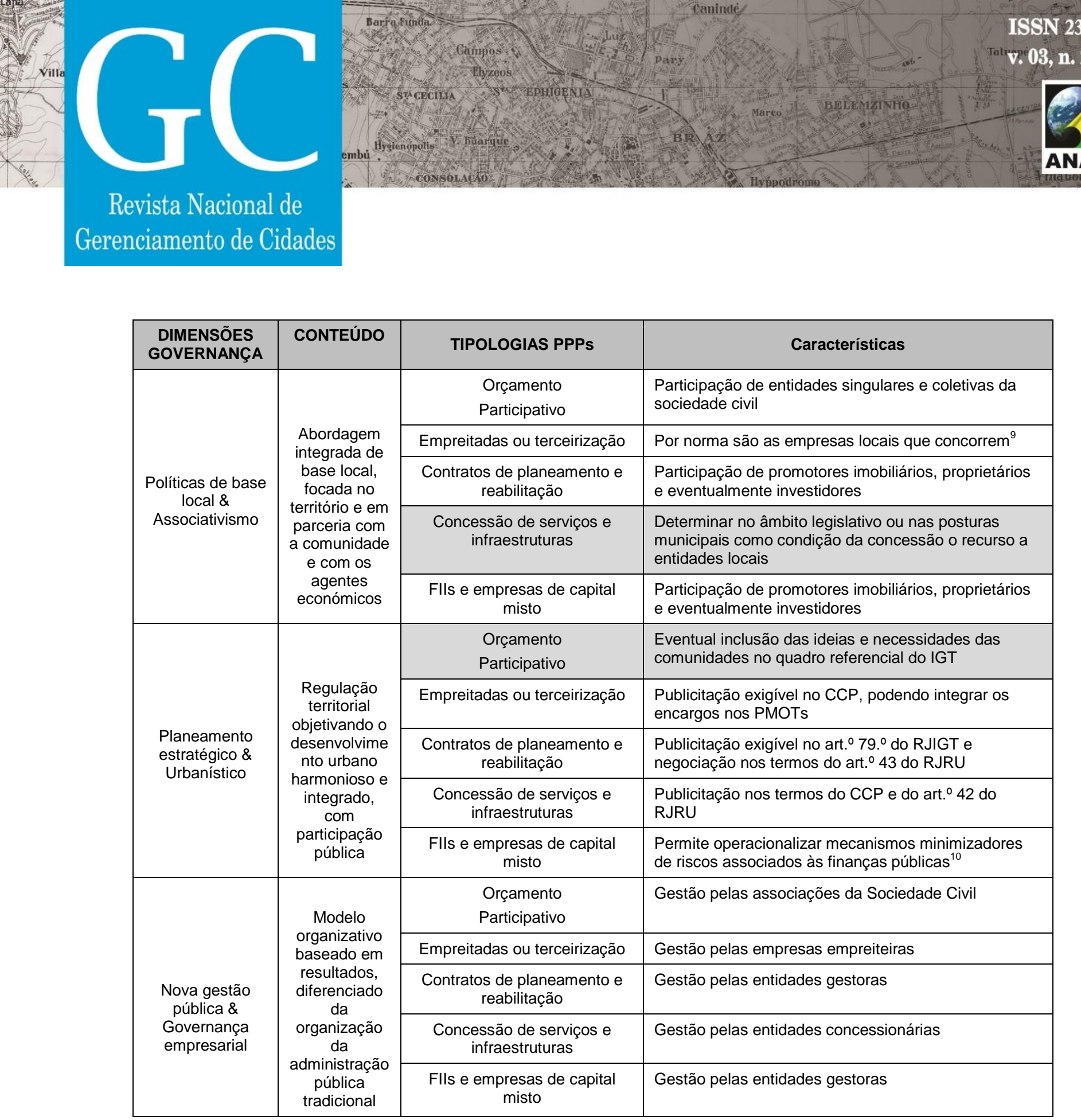

Fonte: CAETANO, 2015 [28]

\section{SEGUNDA ETAPA}

\section{Diagnóstico da situação corrente nas PPP's em Portugal}

Para fazer um diagnóstico do que ocorre no nosso país, relativamente às PPPs, procedemos à CORRELAÇÃO das tipologias de parcerias, comuns em

${ }^{9}$ Razão pela qual em Portugal tantas pequenas e médias empresas (PME) locais entraram em colapso, na sequência da falência dos municípios.

${ }^{10}$ Mas para ser eficaz deve ter monitorização constante. 
Revista Nacional de

Gerenciamento de Cidades

Portugal, com as quatro dimensões da Governança, conforme Quadro 3 abaixo, onde foram discriminadas as cinco tipologias de PPPs, procurando verificar qual o número de incidências mais comuns em cada tipologia.

Quadro 3: Diagnóstico do $n$. ํ de incidências mais comuns nestas tipologias de PPPs

\begin{tabular}{|c|c|c|c|c|c|}
\hline \multirow[b]{2}{*}{ Incidência } & \multirow{2}{*}{$\begin{array}{c}\text { TIPOLOGIAS PPPS } \\
\begin{array}{c}\text { Parcerias público- } \\
\text { privadas }\end{array}\end{array}$} & \multicolumn{4}{|c|}{ DIMENSÕES DA GOVERNANÇA } \\
\hline & & $\begin{array}{l}\text { Política \& } \\
\text { Políticas } \\
\text { públicas }\end{array}$ & $\begin{array}{c}\text { Políticas de base } \\
\text { local \& } \\
\text { associativismo }\end{array}$ & $\begin{array}{l}\text { Planeamento } \\
\text { estratégico \& } \\
\text { urbanístico }\end{array}$ & $\begin{array}{l}\text { Nova gestão } \\
\text { pública \& } \\
\text { Governança } \\
\text { empresarial }\end{array}$ \\
\hline A & $\begin{array}{l}\text { Subsídios, } \\
\text { protocolos, } \\
\text { orçamento } \\
\text { participativo }\end{array}$ & a & a & & a \\
\hline $\mathrm{b}$ & $\begin{array}{l}\text { Empreitadas ou } \\
\text { terceirização } \\
\text { (adjudicação de } \\
\text { obras de construção) }\end{array}$ & b & b & b & $\mathrm{b}$ \\
\hline c & $\begin{array}{l}\text { Contratação de } \\
\text { serviços de âmbito } \\
\text { público (contratos de } \\
\text { planeamento, } \\
\text { reabilitação, etc.) }\end{array}$ & c & c & c & c \\
\hline$d$ & $\begin{array}{l}\text { Concessão de } \\
\text { serviços e } \\
\text { infraestruturas de } \\
\text { gestão e } \\
\text { manutenção } \\
\text { (estacionamento, } \\
\text { águas, etc...) }\end{array}$ & $d$ & & $d$ & $d$ \\
\hline e & $\begin{array}{l}\text { Fundos de } \\
\text { Investimento } \\
\text { Imobiliário e } \\
\text { Empresas de capital } \\
\text { misto }\end{array}$ & e & e & e & e \\
\hline
\end{tabular}

Fonte: CAETANO, 2015 [28]

Da grelha de análise acima (Quadro 3) verifica-se que as Empreitadas ou terceirização (b), a Contratação de serviços de âmbito público (c) e os Fundos de 


\section{Revista Nacional de}

Investimento Imobiliário e empresas de capital misto (e ${ }^{11}$ são as tipologias de PPP's que logram maior número de incidências, neste caso a sua totalidade.

\section{RESULTADOS E DISCUSSÃO}

Os resultados decorrentes da análise do nosso caso de estudo, Parcerias público-privadas (PPP's), demonstram que a incidência nas quatro dimensões da governança apontam para a hipótese de que são bons instrumentos de governança. A literatura sobre o tema corrobora que de fato essas três tipologias de PPP's são exemplos de governança ou "boa governanção". [5] [25]

Do mesmo modo, quanto maior a incidência nas dimensões da governança melhor será como instrumento a utilizar-se na materialização de políticas públicas que objetivam a sustentabilidade territorial e humana.

\section{CONCLUSÕES}

A título de conclusão refira-se que, apesar de ainda ser necessário procederse à validação empírica da grelha de leitura, na nossa ótica esta relação aponta indícios que corroboram a nossa hipótese de que a GOVERNANÇA TERRITORIAL aporta um caminho para a sustentabilidade das comunidades.

\section{REFERÊNCIAS BIBLIOGRÁFICAS}

[1] BARROSO, J. M. (Prefácio), 2010. Estratégia para um crescimento inteligente, sustentável e inclusivo. Comunicação da Comissão EUROPA 2020. Comissão Europeia, Bruxelas.

[2] BARCA, F., 2009. An agenda for a reformed cohesion policy. A place-based approach to meeting European Uunion challenges and expectations.

\footnotetext{
${ }^{11}$ Com reservas porque na área do planeamento estratégico por norma não se verifica a monitorização on-going.
} 


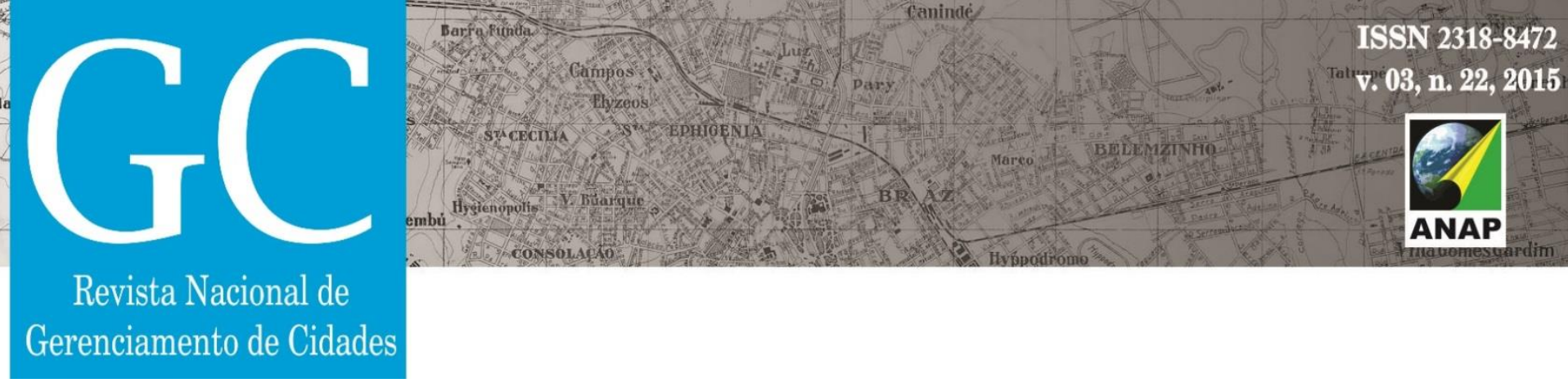

[3] FUDGE, C., SMOOK, R., SOUGAREVA, N., 1996. Relatório Cidades Europeias Sustentáveis Grupo de Peritos sobre o Ambiente Urbano (Publicado pela Comissão Europeia). DG XI — Ambiente, Segurança Nuclear e Protecção Civil, Bruxelas.

[4] CAVACO, C.(Coord.), 2014b. Programa Nacional da Política de Ordenamento do Território Avaliação do Programa de Ação 2007 - 2013 - Relatório (No. ISBN : 978 - 989 - 98477). Direcção Geral do Território, Lisboa - Portugal.

[5] CRESPO, J.L., 2013. Governança e território. Instrumentos, métodos e técnicas de gestão na Área Metropolitana de Lisboa (Tese de Doutoramento). Universidade Técnica de Lisboa, Lisboa - Portugal.

[6] HALL, C.M., 2011. A typology of governance and its implications for tourism policy analysis. Journal of Sustainable Tourism 19, 437 - 457. doi:10.1080/09669582.2011.570346.

[7] ALFORD, R., R., FRIEDLAND, R., 1985. Powers of theory: Capitalism, the State, and democracy. Cambridge University Press, Cambridge.

[8] BEVIR, M., 2011. Governança democrática: uma genealogia. Rev. Sociol. Polit. [online] vol.19, pp. $103-114$

[9] COMPANS, R., 2004. Empreendedorismo urbano: entre o discurso e a prática. Unesp - ANPUR, São Paulo.

[10] EVANS, M., MARSH, D., STOKER, G., 2013. Understanding localism. Policy Studies Vol. 34, No. 4, 401407.

[11] BOSCHI, R.R., 1999. Descentralização, clientelismo e capital social na governança urbana: comparando Belo Horizonte e Salvador. Dados 42, 655 - 690.

[12] CAVACO, C.S., 2014a. From urban sprawl to a compact city policy:The primacy of process over forma, in: ISUF - International Seminar on Urban Form 2014. Presented at the OUR COMMON FUTURE IN URBAN MORPHOLOGY, Porto - Portugal, pp. 15.

[13] ALVES, S.C.N., 2010. O social, o espacial e o político na pobreza e na exclusão: avaliação de iniciativas de regeneração de áreas urbanas "em risco" na cidade do Porto.

[14] BAPTISTA, I., 2008. O Programa POLIS e o "País Desordenado": percepções sobre governância e planeamento urbano em Portugal, in: Cidade e Cidadania: Governança urbana e participação cidadã em perspectiva comparada, Parte II - Governança urbana e cidadania. Imprensa de Ciências Sociais - ICS -UL, Lisboa, pp. 131 - 176.

[15] CABRAL, J., CATITA, A., PINHO, A., DUARTE, A., GONÇALVES, F., CALDEIRA, J., FERREIRA, M. de F., PINHEIRO, Z., 2011. Guia dos Programas de Ação Territorial, Documentos de Orientação DGOTDU 01-2010. DGOTDU, Lisboa - Portugal.

[16] CAVACO, C.(Coord.), 2014b. Programa Nacional da Política de Ordenamento do Território Avaliação do Programa de Ação 2007 - 2013 - Relatório (No. ISBN : 978 - 989 - 98477). Direcção Geral do Território, Lisboa - Portugal.

[17] BRITO, M.F., 2006. A Cantiga das parcerias público-privadas na gestão urbana local. Observanordeste - Textos Especiais 27. 
